\title{
The East-facing Flowers of Drosera tracyi
}

ABSTRACT.-Drosera tracyi, like its sister taxon Drosera filiformis, has inflorescences that face toward the morning sun. When inflorescences were manipulated to face $\mathrm{W}$ vs. E, direction had no effect on pollen removal from anthers or pollen deposition on stigmas. Facing the sun, in this case, is best interpreted as an evolutionary anachronism that no longer has a function, at least not for the enhancement of pollination where D. tracyi now grows in the Panhandle of Florida and adjacent states.

\section{INTRODUCTION}

Plants in a number of taxa have the curious characteristic of presenting their flowers toward the sun. Some track the sun during the course of the day: examples include Papaver radicatum (Hocking and Sharplin, 1965), Dryas octopetala (Kjellberg et al., 1982), Ranunculus adoneus (Stanton and Galen, 1989), and a number of Asteraceae. Others merely point E, facing the dawn, as in the subject of this report, Drosera tracyi MacFarlane in Bailey. Several explanations for the adaptive significance of facing the sun are conceivable: (1) orienting toward the sun may increase the temperature of the flower and thus attract pollinators that like to bask in the warmth; (2) presenting showy petals in direct light rather than in shadow may optimize the stimulus that attracts pollinators; (3) insects may visit flowers more frequently when they do not have to approach them with the glare of a low sun in their eyes; (4) pointing toward the sun may warm floral parts, which might beneficially speed up metabolic activity in pollen grains or in the gynoecium; (5) it may be adaptive for leaves and vegetative shoots to face $\mathrm{E}$ and flowers may simply adopt the same behavior for reasons of homology. Some of these hypotheses have been proposed before and have stimulated interesting research, which has been recently reviewed by Stanton and Galen (1989). In this paper, I provide a new example in which none of the above explanations seems to be currently relevant, suggesting that the ultimate reason (whatever it once was) is now history.

\section{Materials, Methods AND Results}

Drosera tracyi grows in wet savannas in the Florida Panhandle and adjacent regions, where it is colloquially known as snotgrass due to its long sticky insectivorous leaves (Gibson, 1991). The plant is pollinated by pollen-collecting bees, particularly Agapostemon radiatus and several species of Bombus. The pink flowers are presented on an inflorescence that is shaped like a shepherd's crook (Fig. 1, left). Unopened flowers are on the part of the inflorescence that hangs down. Each day, a single flower opens at $0800 \mathrm{~h}$ and closes at noon. The flower is presented to bees almost vertically, and it is located just below the bend in the rachis of the inflorescence. Development proceeds at a precise rate resulting in today's flower becoming placed at tomorrow's bend, and today's bend straightening to become part of the upright stem. It is the bend in the inflorescence that is oriented so that all the flowers, when they open, face the morning sun.

Inflorescences in all populations that I have visited face E. Compass bearings from 114 plants growing near Sopchoppy, Florida, are shown in Figure 1 (right). The direction of flowers ranged from $32^{\circ}$ to $198^{\circ}$, with an angular mean of $100^{\circ} \pm \mathrm{s}^{\prime}=27.6$, i.e., somewhat $\mathrm{S}$ of $\mathrm{E}$, as is the morning sun. The relative length of the mean vector (an index that ranges from 0 for dispersion across all directions to 1 for a unidirectional distribution) was $r=0.89$. To discover whether flowers track the sun during the course of a morning, I took compass bearings every half hour on 15 plants from the time the flowers started to open until they closed. There were no significant trends in these numbers for any of the plants (runs tests P $>0.1$; Sokal and Rohlf, 1981, p. 786).

On 21-22 May 1992 in a wet savanna near Sumatra, Florida, an experiment was done to evaluate whether facing $\mathrm{E}$, as opposed to $\mathrm{W}$, increases pollination success. In the predawn hour, inflorescences were cut at ground level and placed in florists' cut-flower holders. Just as the flowers started to open, one anther was taken from each and preserved in ethanol in a microcentrifuge tube; this anther was used to estimate pollen production for each flower. The inflorescences were then randomly deployed in sets of four at 15 stations located every $20 \mathrm{~m}$ along two transects that ran in the shape of a cross that was centered in a dense natural population of snotgrass. The experiment was repeated on 2 
TABLE 1.-The variance in pollen removal and deposition accounted for by the direction flowers were pointed $(\mathrm{E} / \mathrm{W})$, microsite (Station), and date (Day)

\begin{tabular}{lrcc}
\hline \hline & & \multicolumn{2}{c}{ Mean square } \\
\cline { 3 - 4 } & df & $\begin{array}{c}\text { Rank pollen } \\
\text { removal }\end{array}$ & $\begin{array}{c}\text { Rank pollen } \\
\text { deposition }\end{array}$ \\
\hline E/W & 1 & $97 \mathrm{~ns}$ & $4 \mathrm{~ns}$ \\
Station & 14 & $2038 \mathrm{~ns}$ & $4400^{*}$ \\
Day & 14 & $8494^{*}$ & $1857 \mathrm{~ns}$ \\
E/W $\times \mathrm{S}$ & 1 & $677 \mathrm{~ns}$ & $493^{*}$ \\
E/W $\times \mathrm{S}$ & 1 & $783 \mathrm{~ns}$ & $468 \mathrm{~ns}$ \\
$\mathrm{~S} \times \mathrm{D}$ & 14 & $1279 \mathrm{~ns}$ & $1424 \dagger$ \\
E/W $\times \mathrm{S} \times \mathrm{D}$ & 14 & $792 \mathrm{~ns}$ & $133 \mathrm{~ns}$ \\
Error & 59 & 1075 & 805 \\
\hline Station & 14 & $2045^{*}$ & $4436^{* * *}$ \\
Day & 1 & $8631^{* *}$ & $1887 \dagger$ \\
S $\times \mathrm{D}$ & 14 & $1276 \mathrm{~ns}$ & $1425^{*}$ \\
Error & 89 & 955 & 638 \\
\hline
\end{tabular}

ns $\mathrm{P}>0.1 ; \dagger 0.1>\mathrm{P}>0.05 ; * 0.05>\mathrm{P}>0.01 ; * * 0.01>\mathrm{P}>0.001 ; * * * \mathrm{P}>0.001$

The top panel shows the full mixed model, with East/West being a fixed variable, while Station and Day are random. The higher mean-square terms were tested over lower terms specific to this model (Sokal and Rohlf, 1981, p. 388). The lower panel shows a reduced model, which is pure model II

For the MANOVA, the error sums-of-squares-and-cross-products matrix for the full model was $[63,425.25,32,272.5 / 32,272.5,47,509.25]$, and for the reduced model was $[84,987.29,38,265.56 /$ $38,265.56,56,766.81]$

consecutive days, yielding 30 station-days. In each set of four two of the flowers were oriented to the $\mathrm{E}$, and two were oriented to the $\mathrm{W}$. At noon, the flowers were collected. The four remaining anthers of each flower were preserved in a different microcentrifuge tube, and the stigmas were squashed in glycerin jelly on microscope slides.

The number of pollen grains (actually tetrads of pollen grains) preserved in each microcentrifuge tube was estimated as follows. The contents of each tube were diluted into $1 \%$ saline solution in vials. The vials were sonicated for $1 \mathrm{~min}$ in an ultrasonic water bath to free the pollen from the anthers. The pollen-free anthers were removed with forceps and discarded. Each vial with its pollen suspension was weighed and the weight of the vial when empty was subtracted. An Elzone electronic particle counter (150 $\mu$ orifice) was used to count up to six (or fewer if clogging occurred) $1 \mathrm{ml}$ subsamples. The average of the several counts was then multiplied by the weight of the contents of each vial. The number of tetrads originally produced in four anthers was treated as four times the estimate of the pollen found in the one anther that was separately preserved before flower deployment. The proportion of pollen removed was calculated as (pollen produced - pollen remaining)/pollen produced. The number of pollen grains (tetrads) deposited on stigmas was determined by counting the number of them on the microscope-slide stigma squashes using a compound microscope with an ocular grid.

There were no detectable differences in pollen removal or in pollen deposition between inflorescences facing $\mathrm{E}$ vs. inflorescences facing $\mathrm{W}$, although pollinators were abundant, at least near the center of floral density. A three-way MANOVA was done to determine how direction, station, day and all interactions affected pollen removal and pollen deposition. Both removal and deposition were ranktransformed in order to avoid skewed distributions (Conover and Iman, 1981). The full model was compared to a model purged of all terms containing direction (Table 1): Wilks' Lambda was calculated as the ratio of the determinants of the sums-of-squares-and-cross-products matrices of the two models (Lambda $=0.5868$ with 60 and $118 \mathrm{df})$. Direction clearly did not influence pollination $(\mathrm{P}=0.98)$. 

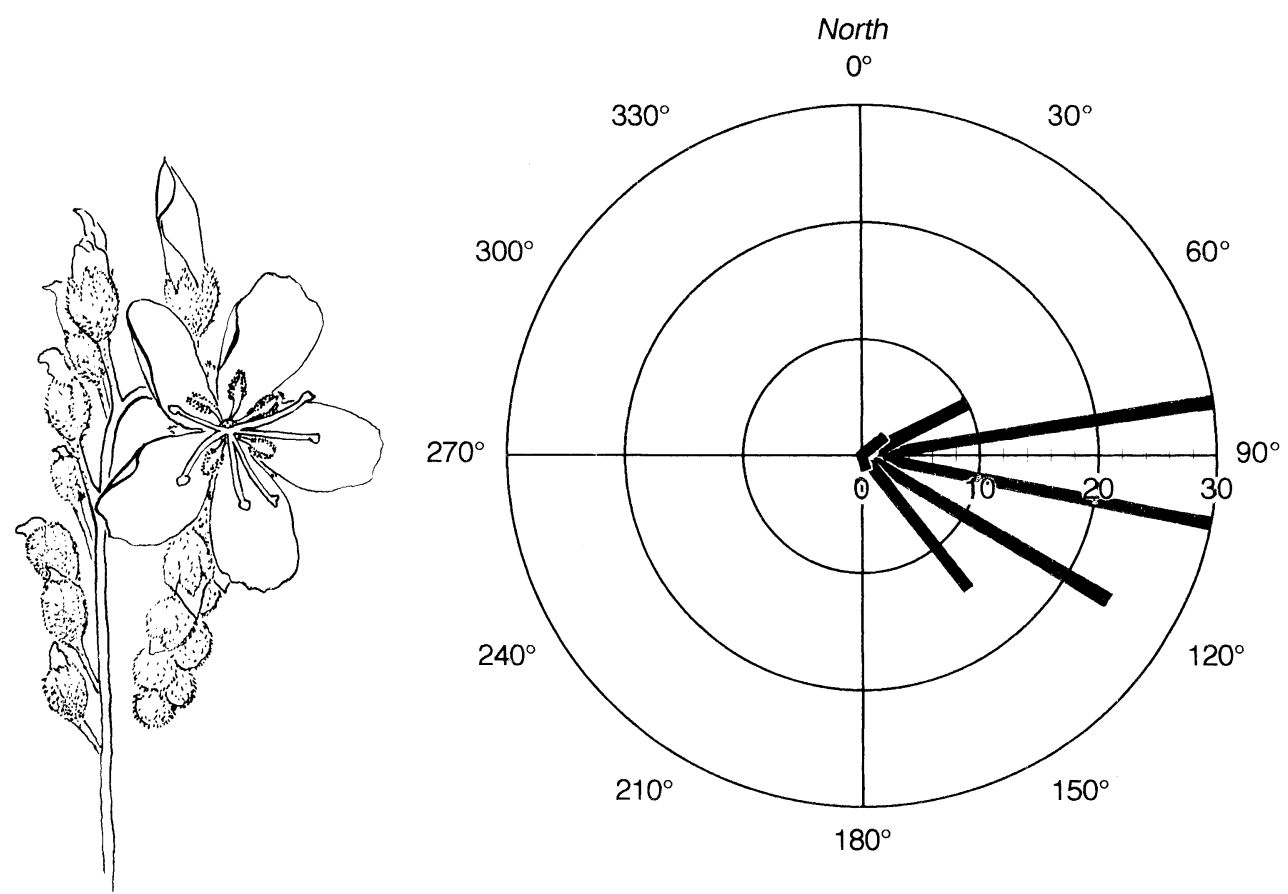

FIG. 1.-The morphology of Drosera tracyi inflorescences and the direction they naturally point. The bars represent the number of inflorescences pointing in directions classed in $20^{\circ}$ intervals

Station and day did (Table 1). An alternative way to evaluate the lack of effect from facing toward the sun is to consider the number of station-days in which more pollen was moved in westward vs. eastward inflorescences. For pollen removal, this was 14 vs. 16 (sign test $\mathbf{P}>0.5$ ); for pollen deposition, 13 vs. $17(\mathrm{P}>0.5)$.

Drosera tracyi is not the only member of its genus with flowers that point E. I also took compass bearings on 100 inflorescences of Drosera filiformis Raf. in Lebanon State Forest, New Jersey. The direction in which $D$. filiformis flowers pointed ranged from $62^{\circ}$ to $178^{\circ}$, with an angular mean of $109^{\circ}$ $\pm s^{\prime}=16.2$ and a relative length for the mean vector of $r=0.96$. The two species have sometimes been treated as distinct only at the subspecific level, but they differ dramatically in size for all organs, in the color of the glandular trichomes, in the height of the inflorescence relative to the leaves, and in the shape of the ovary, as well as in range, habitat and date of flowering. The general morphology of the inflorescence is, nevertheless, the same.

\section{Discussion}

Since Drosera filiformis, as well as Drosera tracyi, has inflorescences that face E, it is parsimonious to assume that this character arose before they split into separate lineages. It therefore might predate the current range and habitat of $D$. tracyi. My experimental results revealed absolutely no effect of the direction that flowers face on pollen removal or pollen deposition. Without effects on these variables, which are the components of fitness that are most proximate to the pollination process, it is hard to imagine that there could be any effect on fitness through enhanced pollination. It seems as if facing the dawn in $D$. tracyi does not currently function to attract floral visitors. The other explanations posed in the Introduction (4 and 5) also seem not to apply: flowers in Florida in May should not need to be warmed to speed up metabolism, and, since the inflorescences point down, it seems unlikely that facing $\mathrm{E}$ is merely a by-product of a physiology that is programmed to reach for the sun. Floral 
tracking of the sun has usually been reported in Arctic and Alpine plants where it has been shown to warm both the flower and its pollinators (Kevan, 1975). It would be interesting to know how many other plants, such as D. tracyi, also have some form of floral heliotropy and whether it affects floral function. The presence of this character in $D$. tracyi is best viewed as an evolutionary anachronism (sensu Janzen and Martin, 1982).

Acknowledgments. - I thank J. Thomson and L. Shapiro for manuscript comments. The National Forest Service kindly allowed me to work on land in its trust. Financial support was provided by a NSF graduate fellowship. This is contribution 900 from Ecology and Evolution at Stony Brook.

\section{Literature Cited}

Conover, W. J. AND R. C. Iman. 1981. Rank transformation as the bridge between parametric and non-parametric statistics. Am. Statistician, 35:124-129.

Gibson, T. C. 1991. Competition among threadleaf sundews for limited insect resources. Am. Nat., 138:785-789.

Hocking, B. AND C. D. Sharplin. 1965. Flower basking by arctic insects. Nature, 206:215.

JANZEN, D. H. AND P. S. MARTin. 1982. Neotropical anachronisms: the fruit the gomphotheres ate. Science, 215:19-27.

KeVAn, P. G. 1975. Sun-tracking solar furnaces in high arctic flowers: significance for pollination and insects. Science, 189:723-726.

KJELlberg, B., S. KARLSSON AND I. KeRSTENSSON. 1982. Effects of heliotropic movements of flowers of Dryas octopetala L. on gynoecium temperature and seed development. Oecologia (Berl.), 54: 10-13.

Sokal, R. R. And F. J. Rohlf. 1981. Biometry, 2nd ed. W. H. Freeman and Company, New York. 859 p.

Stanton, M. L. and C. Galen. 1989. Consequences of flower heliotropism for reproduction in an alpine buttercup (Ranunculus adoneus). Oecologia (Berl.), 78:477-485.

PAUL WILSON, Department of Ecology and Evolution, State University of New York, Stony Brook 11794. Submitted 2 August 1993; accepted 19 November 1993 